\title{
LINGUISTIC COMPLEXITY IN ACADEMIC WRITING: COMPARING TASKS IN L2 ENGLISH
}

\author{
PÄIVI PIETILÄ
}

\section{ABSTRAC T}

Three different types of academic texts written by advanced learners of English were analysed to discover whether they differed from each other in terms of syntactic and lexical complexity. The writing tasks differed in formality and personal involvement. The results were in accordance with earlier studies on L2 writing, in that the most formal texts, the MA thesis conclusions, did not contain any more subordination than the less formal texts. By the same token, the thesis texts showed the longest clauses in the data, suggesting a strong reliance on complex phrases. Another feature previously discovered to characterize formal academic L2 writing, the proportion of general academic vocabulary, was also found in the present study to differentiate the formal thesis texts from the less formal text types.

\section{[1] INTRODUCTION}

Linguistic complexity, together with accuracy and fluency, is one of the main dimensions frequently used to assess L2 proficiency and development. With increasing proficiency, it is natural to expect that complexity, accuracy and fluency in language use also increase. It has been shown, however, that complexity as a concept in SLA research is complex in itself (see the discussion on relative and absolute complexity and their various subcomponents in Bulté and Housen 2012). Linguistic complexity in the present study refers to the breadth (size, range, variation, elaboration) and depth (embeddedness, sophistication) of L2 grammar and lexis (Bulté \& Housen 2012, pg. 27-28).

Complexification as a process is not straightforward either. As stated by systemic functional linguists (e.g. Halliday \& Martin 1993/1996), in both L1 and L2 development, ideas are first expressed through coordination, i.e. in a fairly simple manner. As language competence develops and the speaker wants to express more complex ideas, logical connections between ideas are expressed by means of subordination. In other words, language also becomes more complex. However, the subsequent development does not follow a similar trend. Instead of the sentence structure becoming more and more complex, the most 
advanced level of language use is actually characterized by complex phrases rather than complex sentences, along with higher lexical density (Ortega 2003, pg. 514).

As shown by Biber (2006) and Biber and Gray (2010), the characteristic described above (i.e. phrasal/nominal modifiers embedded in noun phrases rather than increased clausal subordination constituting the principal type of structural complexity) is also evident in L1 English academic writing. According to Biber and Gray (2010), academic writing is commonly believed to be grammatically highly complex and elaborated with long sentences and a great deal of subordination, but this is a stereotypical conception, in the same way as the belief that academic writing is explicit and clear, with logical relations between ideas overtly expressed. In actual fact, English academic writing tends to be both concise, with heavy reliance on phrasal structures, and inexplicit, as meaning relations between grammatical constituents are often unspecified, as is the case with nominalizations and passives, for example. For students, both L1 and L2 readers and writers, this kind of language can be challenging.

In a study on English academic writing by Mazgutova and Kormos (2015), upper-intermediate non-native writers produced text with decreased syntactic embedding, increased complex nominals and an increased proportion of academic vocabulary (from the Academic Word List, Coxhead 2000) after an intensive EAP course, compared with a writing task at the beginning of the course. A group with a slightly lower proficiency in English made even more substantial improvements in lexical diversity. The researchers conclude that lexical and syntactic development towards more academically appropriate and native-like language is possible if students are exposed to a variety of academic reading texts, even though there is no explicit language instruction.

Linguistic complexity also seems to depend on the type of task in which the learner is engaged. This has been central to the two competing theories related to the CAF framework (interrelationships between complexity, accuracy, and fluency). The first of the theories, the Limited Attentional Capacity Model (or the Trade-off Hypothesis) presented by Skehan (Skehan 2009, Skehan \& Foster 1997) claims that language learners cannot focus on all three at the same time, specifically because of attentional limitations. There is bound to be a trade-off between the three components which is basically a matter of not being able to attend to meaning and form simultaneously. Moreover, if faced with a cognitively demanding task, having to deal with difficult subject matter, learners will prioritize content - or meaning - at the expense of form. In other words, they will have difficulty producing complex and accurate language if the task they are engaged in gets more complex. 
The other theory, Robinson's Cognition Hypothesis (Robinson 1995, 2007), on the other hand, claims that cognitively more demanding tasks will lead the learner to use more complex and more accurate language, while fluency may suffer. These theories were first introduced in connection with spoken language and spoken language tasks, but they have also been applied to and tested with written language. All in all, research results have been contradictory. For example, Kuiken and Vedder (2007), when analyzing the writing of French L2 and Italian L2 learners, found that both groups wrote more accurately, but only the French L2 writers showed higher lexical complexity (i.e. used more infrequent words) in the complex task. Ishikawa (2006), on the other hand, found his Japanese L2 learners of English produced structurally more complex language in his more complex task (-Here-and-Now), whereas the results pertaining to lexical complexity were less clear. A study by Xing (2015) produced results showing higher lexical complexity (lexical variation) in the more complex task, while syntactic complexity manifested the opposite tendency, i.e. less embedding (fewer clauses per T-unit).

Similar to the present study, Frear and Bitchener's (2015) research investigated the relationship between writing tasks of differing difficulty (or cognitive task complexity) and the syntactic and lexical complexity apparent in the writing of L2 learners of English. According to their results, increases in task complexity did not result in an increase in syntactic complexity (clauses per T-unit), with adverbial clauses even decreasing significantly, but there was an increase in lexical complexity (expressed by a mean segmental type-token ratio). The authors conclude that while the results for lexical complexity seem to support the Cognition Hypothesis (Robinson 2007), it might also be the case that the learners have prioritized content, as suggested by the Trade-off Hypothesis (Skehan 2009), thus creating a trade-off between two types of complexity (Frear \& Bitchener 2015, pg. 53).

The study reported in this article compared three written academic subgenres from the point of view of linguistic complexity. The texts were written by advanced learners of English, and they represented different degrees of formality and cognitive complexity. In line with an increase in cognitive complexity determined by the writing tasks, a comparison of the texts was expected to reveal either a gradual increase in syntactic and lexical complexity, thus supporting the Cognition Hypothesis (Robinson 2007), or a trade-off between syntactic and lexical complexity, prioritizing lexis (content), as suggested by the Trade-off Hypothesis (Skehan 2009). In sum, the aim of the study was to see whether and in which way the linguistic complexity of written L2 English is determined by task type, more specifically, by the cognitive complexity of 
the task.

\section{[2] THE STUDY}

The study was conducted in the English Department of a Finnish university. The main focus was on linguistic complexity in different types of academic writing, notably writing produced by advanced learners of English. Linguistic complexity was understood in terms of both syntactic and lexical complexity, both of which were measured in several different ways, as explained below.

\section{[2.1] Subjects}

The subjects of the study were 30 university students of English, all with Finnish as their native language. The students were at different stages of their university studies, as 10 of them had recently started them, 10 were in their third or fourth year, and 10 were writing their MA thesis. They had all had about 10 years of English instruction at school before entering the university, and their level of English competence was at least C1 on the Common European Framework of References scale.

\section{[2.2] Data}

The data consisted of three sets of academic writing, ranging from informal and personal texts, through personal but formal to impersonal and formal texts. The first set of texts, informal and personal, were written in connection with a course entitled Prospective Professions, which was meant to help first-year students think about their future careers and the various possibilities that were on offer. We invited several of our alumni who were now working in different kinds of jobs (teachers, translators, interpreters, researchers, commissioning editors, etc.) to come and talk to the students about their career choices. At the very beginning of the course, before any of the guest presentations, the students were asked to write a 400-word essay with the title My professional future, the way I see it at the moment. The students were instructed to write a personal account of their career plans and what they expected from their studies in view of their future working life.

The second writing task, personal but formal, was performed at the end of a course called Four Skills in L2: Introduction to Testing and Research. The students were in their third or fourth year, and they had chosen this optional course as they were interested in second language acquisition. During the course, they had learned about the acquisition of reading, writing, speaking, and listening, and they had been introduced to various ways of testing and researching these four skills. As part of the final course assignment, they were asked to write 
about 2000 words on the contents of the course and their own relationship to a skill of their choice. The instructions read: 'Choose one of the four skills (speaking, writing, reading, listening) and write an essay about your own relationship to that skill, drawing on your own experiences as an L2 user and on your knowledge about the subject.' The essay was, thus, expected to combine personal feelings and experiences with a demonstration of the student's knowledge about the acquisition and study of the four skills in a second language.

The third set of written data consisted of concluding sections of MA theses. The students who had written these texts had chosen the SLA specialization track in their advanced (MA) studies, so the topics were all related to Applied Linguistics, more specifically to second language acquisition. The texts constituted parts of research reports, so they could be characterized as formal and impersonal.

All texts were written in the students' own time, not in class. This means that a certain amount of editing may have taken place. This was deemed not to constitute a problem, as it was a condition that applied to all three text types.

\section{[2.3] Methods of analysis: the measures of complexity used}

Both syntactic and lexical measures of complexity were used in the study to investigate the linguistic complexity of the texts. Following the argumentation of Norris and Ortega (2009), emphasizing the importance of treating syntactic complexity as a multidimensional construct, several different (i.e. nonredundant; see Norris \& Ortega 2009, pg. 560-561) measures were used in the present study. As a general way to evaluate syntactic complexity, $T$-unit length was chosen, although it has also been used by some researchers as an indication of fluency (e.g. Xing 2015). Clauses per T-unit, or, in practice, subordination, was also included, as well as clause length, another frequently-used measure of syntactic complexity. It is noteworthy, however, that, unlike T-unit length, clause length is not a generic measure of syntactic complexity, but, instead, it reveals a specific kind of complexification, namely elaboration at the phrasal level. The frequency of occurrence of particular items or structures that are considered to be linguistically sophisticated (as suggested by, e.g., Ortega 2003, 2012) can also be used to measure linguistic complexity. In this study, the occurrences of Noun Phrases containing Noun modifiers $(\mathrm{N}+\mathrm{N})$ were calculated for this purpose. They belong to the array of linguistic devices that contribute to clause length, similar, for example, to nominalization or other types of pre- or postmodification.

As for lexical complexity, several measures were used. As the simple typetoken ratio is sensitive to text length, extracts of the same length (400 words) 
were submitted to this analysis. Another intrinsic measure of lexical complexity used in the study was lexical density, which indicates the proportion of content words in the total number of words used. Content words being the principal conveyors of information, a text is considered dense if it contains a high proportion of content words. Lexical density is known to increase alongside the formality of the text, so it was to be expected that the most formal of the three text types, the thesis conclusions, would show the highest lexical density.

The two intrinsic measures, type-token ratio and lexical density, describe the vocabulary used in a text without comparing it to anything outside the text itself. They indicate the extent of word repetition or the ratio between content words and function words; in other words, they denote the intrinsic lexical structure of the text. Extrinsic measures, on the other hand, compare the vocabulary used in a text to some outside standard or reference point. In the present study, lexical sophistication, the amount of rare vocabulary, was an extrinsic measure based on the Lexical Frequency Profile (Laufer \& Nation 1995). The proportion of words belonging to frequency bands beyond the first 2000 most frequent English words, as given by the Classic version of the VocabProfile software (Cobb n.d.), was used as the measure of lexical sophistication. This measure ('beyond 2000', B2000) was first employed by Laufer (1995). A subgroup of the B2000 words, Academic Vocabulary (also obtainable with the VocabProfile software and based on the Academic Word List, Coxhead 2000), was analysed separately.

\section{[3] RESULTS AND DISCUSSION}

The results of the study are presented in this section, starting with the measures of syntactic complexity. To give the reader an idea of what kind of language was employed in the three writing tasks, examples of each are given first. The topic My Professional Future prompted rather personal and informal text:

(1) I have always been interested in languages, especially English, and also in different cultures.

(2) At the moment I have absolutely no clue what I want to do when I graduate.

Examples 3 and 4, from the personal but more formal essays (The Four Skills in L2), reveal somewhat more complex sentence structures:

(3) The reason for choosing listening as my point of view in this essay is that 
listening is a skill that, in my opinion, needs more practice than it currently receives in school.

(4) As a user of three different L2s, it is easy for me to see that my language skills are not on the same level in those languages even though I study all of them at the university.

An example sentence from an MA thesis conclusion, the most formal and least personal type of text, demonstrates also a fairly complex sentence structure:

(5) My results implied that the Finnish comprehensive school can provide a good setting for foreign language vocabulary acquisition in that the pupils were shown to learn receptively on average round 700 word families and productively about 400 word families per year during their comprehensive education, estimations in line with previous research on English vocabulary learning in a foreign language context.

Four syntactic measures were employed to analyse the syntactic complexity of the texts. The means and standard deviations are shown in Table 1. The abbreviations stand for the following: PI = personal informal (My Professional Future), $\mathrm{PF}=$ personal formal (Four Skills in L2), IMPF $=$ impersonal formal (MA thesis conclusions), $\mathrm{W} / \mathrm{T}=$ words per $\mathrm{T}$-unit, $\mathrm{W} / \mathrm{Cl}=$ words per clause, $\mathrm{Cl} / \mathrm{T}=$ clauses per $\mathrm{T}$-unit, $\mathrm{N}+\mathrm{N}=$ Noun modified by a Noun, $\mathrm{SD}=$ standard deviation.

\begin{tabular}{ccccc}
\hline & W/T & W/Cl & Cl/T & N+N \\
\hline & Mean SD & Mean SD & Mean SD & Mean SD \\
PI & 14.101 .86 & 6.23 .57 & 2.27 .29 & 1.10 .50 \\
PF & 19.442 .88 & 7.54 .95 & 2.58 .29 & 1.69 .92 \\
IMPF & 22.823 .80 & 9.921 .31 & 2.32 .40 & 4.091 .23 \\
\hline
\end{tabular}

TABLE 1: Syntactic complexity of three text types

Comparing the results obtained for the four syntactic measures in the three types of academic texts, one can see a fairly clear increase in all but one of the measures. The number of clauses per T-unit does not seem to differentiate the text types. These observations are corroborated by the Kruskal-Wallis nonparametric test, which showed a statistically significant difference between the texts in T-unit length, clause length, and the Noun Phrases containing a Noun modifier. According to the post hoc pairwise comparison, the T-units in the formal texts, PF $(p=.010)$ and IMPF $(p=.000)$, were significantly longer than in the informal, personal reflections on professional future prospects. The differ- 
ence between the two formal text types was not statistically significant on this measure.

As for clause length, the situation is slightly different, as the difference between PI and PF did not turn out to be statistically significant, whereas the other two comparisons produced a significant difference. Thus, it can be concluded that the MA thesis conclusions had considerably longer clauses than the other two text types. A similar result was obtained for the Noun Phrases containing a Noun modifier, as the MA thesis texts clearly made much more use of this feature than the other two texts. The figures presented in Table 1 represent the occurrence of these NPs per 100 words. As with clause length, the difference between the two personal texts in the use of NPs containing a Noun modifier, PI (1.10 per 100 words) and PF (1.69 per 100 words), was not statistically significant. The corresponding figure for the MA theses was considerably higher, 4.09 per 100 words. According to the Kruskal-Wallis post hoc pairwise comparison, the difference between PI and IMPF was statistically highly significant ( $p=$ $.000)$, and between PF and IMPF also statistically significant $(p=.007)$.

The results concerning syntactic complexity reported here do not contain any great surprises. It seems that syntactic features do indeed show some degree of complexification as we move from personal and informal writing towards more formal and impersonal writing, with the exception of T-unit complexity as expressed by the number of clauses. This latter result is in accordance with earlier findings concerning the relationship between task complexity and linguistic complexity, as pointed out above. As earlier studies on L2 writing (e.g. Frier \& Bitchener 2015 and Xing 2015, discussed above) have suggested, Tunits, or sentences, do not seem to become more and more complex, with more subordination, in more complex writing tasks. The same phenomenon can be seen in L1 English academic writing, which also uses little subordination, as pointed out with reference to Biber and Gray (2010). Instead, complexification is more prevalent on the phrasal level. This is precisely what can also be detected in the results of the present study, with the length of T-units and especially the length of clauses demonstrating tendency to increase along the informal - formal axis. This is strongly supported by the clear prominence of Noun Phrases containing a Noun modifier in the cognitively most complex texts in the present study, i.e. the formal and impersonal MA conclusions.

The three text types scrutinized in the present study were also analysed from the lexical point of view. The results pertaining to the four lexical measures (type-token ratio, lexical density, lexical sophistication, i.e. B2000, and the proportion of academic vocabulary) are shown in Table 2. The abbreviations stand for the following: PI = personal informal (My Professional Future), PF 
= personal formal (Four Skills in L2), IMPF = impersonal formal (MA thesis conclusions), $\mathrm{T} / \mathrm{T}=$ type-token ratio, $\mathrm{LD}=$ lexical density, $\mathrm{AWL}=$ academic word list, $\mathrm{SD}=$ standard deviation.

\begin{tabular}{|c|c|c|c|c|}
\hline & $\mathrm{T} / \mathrm{T}$ & LD & B2000 & AWL \\
\hline & Mean SD & Mean SD & Mean SD & Mean SD \\
\hline PI & .47.04 & .46.03 & $6.80 \quad 1.42$ & 3.81 .80 \\
\hline PF & 03. & $.52 \quad .03$ & 12.873 .06 & $6.27 \quad 2.21$ \\
\hline IMPF & .05 . & $.56 \quad .02$ & $18.48 \quad 2.09$ & 9.941 .51 \\
\hline
\end{tabular}

TABLE 2: Lexical complexity of three text types

As was the case with the syntactic measures discussed, one of the measures used to assess lexical complexity did not reveal any differences between the three text types. Looking at Table 2, the figures indicating the type-token ratio, i.e. the variety of the vocabulary employed in the texts, are very uniform across the three genres. As mentioned earlier, text extracts of the same length (400 words) were submitted for this analysis, so the figures are comparable. It is not evident why this intrinsic lexical measure yielded such similar results, regardless of the differing degree of formality of the texts. It is possible that the extracts used for this analysis were rather short to give a realistic picture of the variation of the vocabulary employed.

The other three lexical measures revealed differences between the three texts, as indicated by the independent samples Kruskal-Wallis test. Even the other intrinsic lexical measure, lexical density, proved adequate to differentiate the personal informal texts from the two formal texts, according to the post hoc test. The difference was statistically significant between the personal informal texts and the personal formal texts at the $p<.05$ level, and the personal informal texts and the impersonal formal thesis texts at the $p=.000$ level. This is in accordance with what is generally known about lexical density: the proportion of content words in the total number of words tends to increase with increased formality and is typically much higher (above .40) in written than in spoken language (Ure 1971).

A glimpse at the results of the two extrinsic vocabulary measures, B2000 and academic vocabulary (AWL), would suggest that rather considerable differences could be found in the texts based on these analyses. Indeed, the Kruskal-Wallis nonparametric test confirmed that these measures of lexical sophistication revealed statistically significant differences between the texts. The B2000 figure denotes the proportion of words that do not belong to the first 2000 most frequent English words. They are, therefore, indications of the mastery and use of 
infrequent vocabulary. It is natural that their use is characteristic of both formal and specialised texts. As indicated by the Kruskal-Wallis post hoc test, a statistically significant difference was found between the personal informal texts and the personal formal texts $(p<.05)$, and even more clearly between the personal informal texts and the impersonal formal thesis texts $(p=.000)$. The difference between the two formal texts was almost statistically significant ( $p=$ .051). It is, of course, to be expected that a thesis text would contain more infrequent words than a text of a more personal nature. Some of the B2000 vocabulary used in the theses are bound to be discipline-specific, technical words, even though the section analysed was the conclusion of the thesis. A subgroup of B2000, however, consists of academic vocabulary which is not disciplinespecific but contains words which are needed in academic texts of all kinds. This was the final lexical measure in the present study (AWL).

As can be seen in Table 2, the proportion of academic vocabulary grows quite clearly from informal personal, through formal personal, to formal impersonal texts. This was also confirmed by the Kruskal-Wallis test. According to the post hoc tests, the MA thesis texts seem to contain a considerably greater amount of academic vocabulary than the other two text types, the difference being statistically significant between the thesis texts and the personal informal texts at the $p=.000$ level and even between the theses and the personal formal texts at the $p<.05$ level. This was both an expected and an unexpected finding. On one hand, it is understandable that research reports, such as MA theses, contain a large amount of academic vocabulary, but at the same time the more personal academic texts (the informal essays on professional prospects and the more formal essays on foreign language skills) could also be expected to show large proportions of academic words, given that these words are of general nature and not limited to a particular academic discipline.

The figures appearing in earlier studies for general academic vocabulary (AWL) tend to centre round $10 \%$ (fom $9.1 \%$ to $12.0 \% \%$ in Coxhead 2000). In a study involving groups of Finnish and Czech university students comparable to the subjects of the present study, Pietilä found on average $9.72 \%$ of the vocabulary of concluding sections of MA theses written by Finnish students to contain academic words. In the corresponding data from Czech students the figure was 9.95\% and from native speakers of English 11.46\% (Pietilä 2015, pg. 115). An analysis of a section of the Brown corpus including seven different academic domains showed a mean AWL coverage to be $11.60 \%$, whereas the corresponding figure for popular expository writing was about half of that, 5.56\% (Cobb \& Horst 2004). It is therefore no wonder that words representing the AWL are somewhat less frequent in L2 student writing, compared with texts written by 
native speakers of English.

As shown by the results of the lexical complexity analysis, the personal texts in the present study contain very few academic words. Example 6 comes from My Professional Future, and it has no AWL words at all.

(6) When I started my English studies at the University this fall, I was quite sure I want to be a translator in the future. However, I have already changed my mind...

In examples 1-4 above, only the word culture in example 1 belongs to the Academic Word List. To illustrate the frequency of AWL vocabulary in the most formal texts, the MA thesis conclusions, the same sentence as in example 5 above is given here, with the AWL words in italics:

(7) My results implied that the Finnish comprehensive school can provide a good setting for foreign language vocabulary acquisition in that the pupils were shown to learn receptively on average round 700 word families and productively about 400 word families per year during their comprehensive education, estimations in line with previous research on English vocabulary learning in a foreign language context.

Example 7 also illustrates the finding that Noun Phrases containing a Noun modifier were a typical feature of the MA thesis texts (vocabulary acquisition, word families, vocabulary learning, foreign language context). In the other examples given here, only example 4 has one NP of this type (language skills).

\section{[4] CONCLUSION}

The study reported here focused on linguistic complexity as it manifested itself in three different writing tasks, each representing academic writing in a foreign language but differing from each other in terms of formality and personal stance. The results indicated that there were differences between the texts in terms of syntactic and lexical complexity, the informal texts (essays on the students' professional future) showing the shortest $\mathrm{T}$-units, the lowest lexical density, and the smallest proportion of infrequent vocabulary. The most formal and impersonal texts, the MA thesis conclusions, on the other hand, demonstrated the longest clauses, the greatest number of Noun Phrases containing a Noun modifier, and the largest proportion of academic vocabulary (words from the Academic Word List, Coxhead 2000). The personal but formal texts (essays on the four skills in a second language) occupied a middle ground, producing complexity results which sometimes tallied with the personal informal texts (in 
clause length, Noun Phrases containing a Noun modifier) and sometimes with the impersonal formal thesis texts ( $\mathrm{T}$-unit length, lexical density, the proportion of infrequent vocabulary, as measured with the B2000 feature).

The results were generally in accordance with earlier findings obtained in studies on L2 writing. Tasks involving cognitive complexity, such as research reports (MA theses in the present study) have been found to favour complex phrases, the use of which would also explain the fact that the longest clauses in the present study were found in the MA thesis texts. The frequent use of Noun Phrases containing a Noun modifier by the MA thesis writers similarly confirms earlier descriptions of English academic writing. As for the amount of subordination, an issue which has received a fair amount of attention previously, the results of the present study seem to be in accordance with the earlier finding that subordination does not characterize formal academic writing style. All in all, it seems that the writing competence of students of English develops to meet the demands of the tasks they are given, as they advance in their studies. Apparently, the fact that they are exposed to various types of academic texts written in English on courses and in seminars helps them to acquire some of the academic style that is prevalent in the international English-language research community.

As for the results supporting either the Cognition Hypothesis (Robinson 2007) or the Trade-off Hypothesis (Skehan 2009), nothing very conclusive can be said. However, there seems to be a tendency for certain aspects of both syntactic and lexical complexity to increase as a function of increasing task complexity, thus meeting the expectations of the Cognition Hypothesis.

The study reported here was a small-scale study involving three different academic text types produced by L2 writers. In future, a longitudinal research design with the same writers producing texts with different degrees of formality or cognitive complexity at different points in their language learning careers would yield interesting results about the relationship between task type, L2 proficiency and linguistic complexity.

\section{[5] ACKNOWLEDGMENTS}

I would like to thank two anonymous reviewers for their insightful comments on an earlier version of the paper.

\section{REFERENCES}

Biber, Douglas. 2006. University Language: A Corpus-based Study of Spoken and Written Registers. John Benjamins.

Biber, Douglas \& Bethany Gray. 2010. Challenging Stereotypes about Academic 
Writing: Complexity, elaboration, explicitness. Journal of English for Academic Purposes 9. 2-20.

Bulté, Bram \& Alex Housen. 2012. Defining and Operationalising L2 Complexity. In Alex Housen, Folkert Kuiken \& Ineke Vedder (eds.), Dimensions in L2 Performance and Proficiency: Complexity, Accuracy and Fluency in SLA, chap. 2, 2146. John Benjamins.

Cobb, Tom. n.d. The Compleat Lexical Tutor. Computer software. Available online at www.lextutor.ca.

Cobb, Tom \& Marlise Horst. 2004. Is There Room for an Academic Word List in French? In Paul Bogaards \& Batia Laufer (eds.), Vocabulary in a Second Language: Selection, Acquisition and Testing, chap. 2, 15-38. John Benjamins.

Coxhead, Averil. 2000. A New Academic Word List. TESOL QUARTERLY 34(2). 213238.

Frear, Mark Wain \& John Bitchener. 2015. The Effects of Cognitive Task Complexity on Writing Complexity. Journal of Second Language Writing 30. 45-57.

Halliday, M.A.K. \& J.R. Martin. 1993/1996. Writing Science: Literary and Discursive Power. Falmer Press.

Ishikawa, Tomohito. 2006. The Effect of Manipulating Task Complexity Along the ( \pm Here-and Now) Dimension on L2 Written Narrative Discourse. In María del Pilar García Mayo (ed.), Investigating Tasks in Formal Language Learning, chap.7, 136-156. Multilingual Matters.

Kuiken, Folkert \& Ineke Vedder. 2007. Task Complexity and Measures of Linguistic Performance in L2 Writing. IRAL 45. 261-284.

Lambert, Craig \& Judit Kormos. 2014. Complexity, Accuracy, and Fluency in Task-based L2 Research: Toward More Developmentally Based Measures of Second Language Acquisition. Applied Linguistics 35(5). 607-614.

Laufer, Batia. 1995. Beyond 2000 - A Measure of Productive Lexicon in a Second Language. In Lynn Eubank, Larry Selinker \& Michael Sharwood Smith (eds.), The Current State of Interlanguage, 265-272. John Benjamins.

Laufer, Batia \& Paul Nation. 1995. Vocabulary Size and Use: Lexical Richness in L2 Written Production. Applied Linguistics 16(3). 307-322.

Mazgutova, Diana \& Judit Kormos. 2015. Syntactic and Lexical Development in 
an Intensive English for Academic Purposes Programme. Journal of Second Language Writing 29. 3-15.

Norris, John M. \& Lourdes Ortega. 2009. Towards an Organic Approach to Investigating CAF in Instructed SLA: The Case of Complexity. Applied Linguistics 30(4). 555-578.

Ortega, Lourdes. 2003. Syntactic Complexity Measures and their Relationship to L2 proficiency: A Research Synthesis on College-level L2 Writing. Applied Linguistics 24(4). 492-518.

Ortega, Lourdes. 2012. Interlanguage Complexity. A Construct in Search of Theoretical Renewal. In Bernd Kortmann \& Benedikt Szmrecsanyi (eds.), Linguae and Litterae: Linguistic Complexity: Second Language Acquisition, Indigenization, Contact, 127-155. Walter de Gruyter.

Ortega, Lourdes. 2015. Syntactic Complexity in L2 Writing: Progress and Expansion. Journal of Second Language Writing 29. 82-94.

Pietilä, Päivi. 2015. Lexical Diversity in L2 Academic Writing. In Päivi Pietilä, Katalin Doró \& Renata Pípalová (eds.), Lexical Issues in L2 Writing, chap. 5, 105-125. Cambridge Scholars Publishing.

Robinson, Peter. 1995. Task Complexity and Second Language Narrative Discourse. Language Learning 45(1). 99-145.

Robinson, Peter. 2007. Task Complexity, Theory of Mind, and Intentional Reasoning: Effects on L2 Speech Production, Interaction, Uptake and Perceptions of Task Difficulty. International Review of Applied Linguistics 43(3). 193213.

Skehan, Peter. 2009. Modelling Second Language Performance: Integrating Complexity, Accuracy, Fluency and Lexis. Applied Linguistics 30(4). 510-532.

Skehan, Peter \& Pauline Foster. 1997. Task Type and Processing Conditions as Influences on Foreign Language Performance. Language Teaching Research 1(3). 185-211.

Ure, Jean. 1971. Lexical Density and Register Differentiation. In G.E. Perren \& J.L.M. Trim (eds.), Applications of Linguistics, 443-452. Cambridge University Press.

Xing, Jiaxin. 2015. The Effects of Increasing Task Complexity on EFL Learners' Writing Performance. Studies in Literature and Language 11(4). 34-39. 
CONTACT

\section{Päivi Pietilä}

University of Turku

paipi@utu.fi 
